\title{
A Figura Poliédrica de Calógeras
}

E. D'ALMEIDA VITOR

Redator do Ministério da Educação e Cultura.

Com o passar dos anos, parece que sua figura adquire maiores proporções. É que afrouxados os sentimentos de bemquerer de uns, e os ressentimentos políticos de outros, que comprimiam a lembrança de sua individualidade singularmente vigorosa, extraordinária em seus atributos intelectuais, morais e criativos, torna-se possível uma melhor avaliação.

O problema está, já agora, na escolha de uma das faces de sua personalidade poliédrica, para expô-la, analisá-la, destacando-a. Engenheiro de Minas, economista, sociólogo, parlamentar, administrador, diplomata, conferencista, escritor, historiador, sob qualquer dêsses ângulos que o visualisemos, Calógeras se nos impõe como um dos maiores homens de sua época.

Sobremodo, não poderão deixar de ser levados à conta de mérito, sua consciência cívica, seu entusiasmo criador e a sinceridade objetiva na resolução dos problemas que, circunstancialmente, Ihe foram propostos à solução; mesmo quando se mostrou inflexivel nas decisões, a ponto de parecer irrelevante. Não foram poucas as antipatias que atraiu por essa atitude; e, que, decerto, também terão contribuído para a limitação coeva de sua popularidade, na deformação intencional de seu caráter, como se êle fôsse, por essa suposta intransigência, um atrabiliário e intratável. Verdade, porém, é que, por princípios, jamais antecipou soluções a problemas desconhecidos; mergulhava fundo no conhecimento de cada assunto, de lá retirando os elementos necessários a uma conceituação própria, que a defenderia, de então, com firmeza, com denôdo.

Doutra parte, sua época tumultuada por um difícil processo político, obrigou-o a opções nem sempre condescendentes. Tal foi a desburocratização dos serviços públicos que empreendeu na Agricultura, como na Fazenda, tendo de opor-se à indigni- 
dade funcional com igual firmeza como à defraudação organizada do Erário. No Exército, promovera a transformação de sua infra-estrutura; e com ela, da própria mentalidade prevalecente na corporação; não condescendendo com a indisciplina, como no caso da sedição do Forte de Copacabana, no Rio de Janeiro, a 5 de julho de 1922 - cuja romântica rendição (fotografada por Mafra) passou à história como os 18 do Forte: ${ }^{1}$ e que, certamente, haveriam de incompatibilizá-lo com grupos poderosos, interessados na manutenção daquele status, que iriam mover-Ihe insidiosa campanha; do que resultou lamentàvelmente, retardasse o reconhecimento de sua ação administrativa, de sua incontestável honestidade pessoal, ademais, do sentido eminentemente patriótico, que suas iniciativas representam.

E, no entanto, pessoalmente, Calógeras era - a julgar por depoimentos insuspeitos - bom, amável, humilde, a ponto de não hesitar em retroceder numa decisão, desde que se conscientizasse de haver cometido um êrro; sendo afetuoso para com a espôsa e os amigos. Pires Brandão, para caracterizar sua grandeza humana, para acentuar a falta de caráter de alguém, comentava: "Fulano não presta: chega até ao ponto de falar mal do Calógeras"; ${ }^{2}$ o que nos leva a admitir, sem receio de engano, ter sido êle, grande e bom, dessa argila com que o Destino modela os sêres de exceção; capaz de impor-se aos que o conheciam fora da cena administrativa com afeto; com ternura. E, pois, válida, a observação de Antônio Gontijo de Carvalho, de que "Calógeras não foi bem compreendido em seu meio" - ao apreciar o Estadista. ${ }^{3}$

Nascido no Rio de Janeiro-GB, a 19 de junho de 1870, descendia João Pandiá Calógeras de imigrantes gregos (em segunda geração), que se fixaram no Brasil em princípios do século XIX. Educaram-no os avós, orientando seus primeiros estudos, capacitando-o para, já aos 5 anos, ler e escrever; desenvolvendo-lhe, metòdicamente, a inteligência, de modo a que, aos 14 anos, no Imperial Colégio Pedro II, viesse a prestar, de uma só vez, os exames das matérias preparatórias - em número de

1. Em verdade, a aceitarmos o testemunho do Marechal-do-Ar Eduardo Gomes, que ainda no pôsto de Tenente do Ex., participou da sedição, e em cuja oportunidade foi ferido, eram 11 e não 18, os "Heróis do Forte", sob o comando do Tenente Siqueira Campos, entre os quais, se imiscuira o civil Otávio Correla.

2. Apud Antônio Gontijo de Carvalho, in Calógeras, 1935.

3. Antônio Gontijo de Carvalho, in ob. cit. 
13, necessárias ao curso superior na Escola de Minas, em Ouro Prêto-MG, à qual se destinava. Logo constataria, entretanto, a inutilidade dêsse esfôrço, ao ter negada sua matrícula, face à falta de idade regulamentar.

Compensou-o, contudo, a amizade conquistada a Capistrano de Abreu (1853-1927) - que participara da banca examinadora, e que Calógeras haveria de manter por tôda vida, exaltando-a num excelente retrato gráfico do eminente historiador, em seu livro Res Nostra; como haveria de compensar-Ihe a distinção recebida do Colégio, convidando-o, no ano seguinte (1885) com apenas 15 anos, destarte, para integrar a banca examinadora de História, Geografia, Francês e Inglês, em cuja tarefa se houve com aplaudido rigor.

O curso de engenharia iniciado em 1886, realizou-o com aplicação e brilho, conquistando, ao final (1890), com o primeiro lugar de sua turma, o Prêmio de Viagem à Europa, que jamais o reclamou. Logo casaria (1891) com uma jovem de tradicional família mineira, integrando-se, definitivamente, por êsse meio, na terra; e com tal dedicação, que, não raro, tem sido confundida sua naturalidade de carioca. Não deixaria descendentes, do seu matrimônio, o que, uma e outra vez se dimensionava em magoada confidência a amigos mais íntimos.

Sua atividade profissional teve início em Santa Catarina, onde se entregou interessado a uma série de pesquisas geológicas, cujos resultados reuniu-os nas monografias (hoje raríssimas) 0 manganês de Cariguaba, $\mathbf{O}$ Meteorito de Santa Catarina e Le fer nicklé de Sainte Catherine, contestando afirmações consagradas, para demonstrar a existência de ferro e manganês na região.

Pouco menos de dois anos depois, deixava o Estado sudestino, contratado pelo Govêrno de Minas Gerais, que o situou como engenheiro-residente na região do Triângulo Mineiro. Publica, nessa época (1893), seu primeiro livro de fôlego, Os Minérios de Ferro e as Minas de Ouro Nacionais, sôbre o qual apoiaria seu livro (ainda hoje válido) As Minas do Brasil e sua Legislação, em 3 volumes, publicados sucessivamente, entre 1904 e 1905 e considerado como "verdadeira Enciclopédia de Geologia Econômica"; ${ }^{4}$ tanto mais importante, por sua orientação nacionalista; com irrecusáveis implicações na conduta posterior do Govêrno Federal.

4. Antônio da Rocha Almeida, João Pandiá Calógeras, in Vultos da Pátria, vol. II, 1964. 
Envolvido, inadvertidamente, em questiúnculas políticas municipais, achou por bem deixar Uberaba, indo residir em Belo Horizonte, onde foi aproveitado, inicialmente, como Assessor Técnico da Secretaria de Viação e Obras, e, depois, como Diretor de Mineração. A repercussão de seus trabalhos geológicos havia aberto perspectivas novas à sua vida, encaminhando-o para a política, já aos 27 anos, levando-o ao Congresso, como deputado federal. Sua carreira parlamentar se estenderia de 1897 a 1914, apenas interrompida durante a legislatura de 1900.

Sua passagem pela Câmara dos Deputados está marcada de maneira indelével, não apenas pela operosidade de sua atuação, e suas freqüentes intervenções sempre eruditas, impessoais apolíticas; como por haver vivido ali momentos que transcenderiam no tempo: já defendendo a recusa de autorização para que fôsse. processado Francisco Glicério; já na sessão secreta na qual se debatia o problema acreano (1901); na qual falaria por horas a fio, ouvido, ao fim, por não mais de cinco de seus pares; êsse fato, aliás, haveria de o repetir em 1913, falando por várias horas consecutivas, para um auditório apenas um pouco maior, argumentando rubricas do Orçamento da União. Jamais foi, realmente, um orador vocacional; senão, que seu raciocínio lógico, a clareza de seus argumentos apoiados em conhecimentos indiscutíveis, a facilidade de sua expressão, davam aos seus discursos um tom quase didático sem ser enfático. Era, porém, ágil e contundente em sua réplica, ao ser aparteado.

Deixaria a Câmara dos Deputados para participar do Govêrno do Presidente Venceslau Brás - iniciado a 15 de novembro de 1918, quando assumiu, primeiramente, a direção do Ministério da Agricultura, Indústria e Comércio. ${ }^{5} \mathrm{O}$ destino se comprazia em dar-lhe oportunidade de mostrar-se em sua real vocação, que era a de administrador, como tal marcando sua presença naquela Secretaria de Estado. Sua primeira preocupação foi a desburocratização dos serviços, através de reforma administrativa; logo voltando-se para a reorganização da Diretoria do Serviço Veterinário - que haveria de merecer também seus cuidados, quando Ministro do Exército, ${ }^{6}$ anos depois - simultâneamente, criando com serviço específico, condições de defesa da cultura do algodão; promovendo, a seguir, a organização de Crédito Agrícola; estimulando o sistema cooperativo; criando incentivos novos para a indústria

5. Primitiva denominação do atual Ministério da Agricultura.

6. Denominação atual do antigo Ministério da Guerra. 
pastoril; ademais de pôr em execução a Lei que leva o seu nome, que regulamenta a propriedade das Minas em território nacional. O afastamento do titular da Fazenda (Sabino Barroso Filho), deu-lhe o encargo interino e cumulativo dessa pasta, em junho de 1915, na qual seria efetivado a 11 de agôsto seguinte, com afastamento definitivo do seu colega e amigo, por enfermidade, quando deixaria o Ministério da Agricultura, Indústria e Comércio, onde em nove meses de atuação dinamizara os serviços gerais.

Recebera o cargo de Ministro da Fazenda num dos momentos críticos das finanças nacionais: escassas rendas, despesas supérfluas com um vasto funcionalismo ocioso e oneroso, dividas flutuantes, e um segundo funding ${ }^{7}$ recente, com a sobrecarga de um estado de guerra na Europa, no qual iriamos ser envolvidos com direta participação no envio de uma fôrça expedicionária, o que agravaria nossa situação interna, com o bloqueio do único caminho de que dispúnhamos para um intercâmbio de produtos entre o S. e N. - o Atlântico; tudo a exigir um super-esfôrço, para evitar que um caos maior arrastasse o País à insolvência de seus compromissos, provocando a falência das instituições. Teve Calógeras de tomar medidas contrárias a interêsses políticos e financeiros de uns tantos; e que as manteria, sem embargo dos grupos de pressão organizados pelos atingidos; sem se ter valido do expediente de aumento do meio circulante; tanto mais, ante a resistência do Congresso em permitir novas emissões de papel-moeda; mas, por meio da contenção drástica das despesas públicas e do combate frontal e decisivo ao contrabando organizado, e o acuamento aos defraudadores do Tesouro Nacional. Superara a crise, com fabuloso esfôrço, sem mais apoio que os escassos recursos remanescentes, dirigidos com determinação construtiva, obtendo, como efeito, a recuperação do equilíbrio econômico-financeiro da Nação.

Nenhum outro homem público brasileiro, no entanto, terá catalizado em sua época tamanha corrente de ressentimento quanto Calógeras, que se viu atingido pela calúnia dos prejudicados em seus interêsses antinacionais, numa campanha destinada a "criar-lhe uma atmosfera de hostilidade, de descrédito e suspeita". ${ }^{8}$ Calógeras resistiu o quanto pôde; mas,

7. Vocábulo inglês, também usado na forma funding-loan, de curso internacional na nomenclatura econômica, para caracterizar operação financeira da reunião de dividas diversas de uma Nação, para sua consolidação em têrmos de reavaliação e o estabelecimento de novos prazos de pagamento.

8. Antônio Gontijo de Carvalho, in ob. cit. 
num momento, preferiu deixar a cena administrativa para que melhor o julgassem; procurando explicar, em carta ao Presidente da República, o sentido de seu pedido de exoneração (10-7-17) em têrmos tais: "Receio que minha ação, em vez de auxílio, seja um estôrvo. Não se dirige a Fazenda Pública, principalmente em períodos como êste que atravessamos, sem suscitar graves dificuldades, e sem incorrer, conscientemente, na impopularidade que decorre das restrições impostas pelo momento. Êsse é o preço do cumprimento do dever". 9

Haveria a História de julgá-lo em seus atos, fazendo-lhe justiça, ao reconhecer a lisura de seu caráter, o sentido objetivo de suas resoluções, a consciência cívica que o orientou no trato da coisa pública.

Mesmo amargurado pela infamante campanha movida, visando denegrir-lhe a reputação, nem por isso recusou-se a participar da Delegação do Brasil à Conferência de Paz, em Versalhes, convocada com o Armistício da Grande Guerra, em 1918, e que tinha Epitácio Pessoa como chefe. Fôra essa, talvez, uma maneira de o Presidente Venceslau Brás demonstrar públicamente a Calógeras seu aprêço pela colaboração em dois Ministérios; e, por certo, caracterizar sua solidariedade contra 0 èsguicho de lama com que procuravam atingi-lo seus opositores, tentando, assim, desmerecê-lo, no respeito público.

O encargo diplomático, não era, entretanto, um simples gesto de consideração do Chefe da Nação; mas, o reconhecimento de méritos evidenciados anteriormente em sua atuação na III Conferência Pan-americana do Rio de Janeiro, de 1906; ${ }^{10}$ mesmo na IV Conferência Pan-americana, reunida em Buenos Aires - para a qual nomeado, não chegando a participar pessoalmente, por haver sido retardada, maliciosamente, pela Câmara dos Deputados, a licença, como a seu colega Germano Hasslocker, para se ausentarem do país; a qual emprestara, sem embargo, sua colaboração para o sucesso brasileiro, com a tese La Politique Monetaire du Brésil, que elaborara em três meses, por solicitação do Chanceler Rio Branco - por indicação de Leopoldo Bulhões, então Ministro da Fazenda. Como titular das Finanças (1916), havia, ainda, chefiado a representação do Brasil no Congresso Financeiro Pan-americano, reunido em Buenos Aires, onde foi a "figura central da Conferência". 11

9. Apud Antônio Gontijo de Carvalho, in ob. cit.

10. Chefiada por. Joaquim Nabuco, tendo mais a integrá-la Graça Aranha, Assis Brasil, Amaro Cavalcanti e Gastão da Cunha.

11. Antônio Gontijo de Carvalho, in ob. cit. 
Dêste modo, sua indicação para integrar a Delegação Brasileira à Conferência de $\mathrm{Paz}$, em Versalhes, tinha honrosos precedentes. Não causou estranheza, assim, que ali se erguesse sombranceiro, entre seus eminentes companheiros, 12 para enfrentar a suspicácia das chamadas Grandes Potências, lideradas por Georges Clemenceau, tentando negar às nações menores o direito de voto e a condição de poder decidir. E quando Epitácio Pessoa, eleito Presidente da República, em sucessão a Rodrigues Alves, ${ }^{13}$ teve de retornar ao Brasil, seria a Calógeras a quem transferiria seu lugar de chefe da Delegação.

Sua Missão Diplomática na Europa não terminara, todavia, na França, onde participara da Fundação da Sociedade das Nações - de iniciativa do presidente norte-americano Woodrow Wilson, a quem apoiara desde o primeiro momento. Em seguida, foi desdobrada numa Missão Comercial na Inglaterra, que a desempenhou com eficiência e brilho, antes de regressar ao Brasil - já escolhido para exercer o cargo de Ministro do Exército.

Decerto, não era também uma escolha gratuita, porque "nenhum civil se consagrara aos estudos militares nem assumira atitudes tão destemidas nas discussões sôbre a defesa nacional como Calógeras", como bem o acentuou Antônio Gontijo de Carvalho, 14 basta, para senti-lo, que se manuseie os Anais da Câmara dos Deputados, de 1903 a 1914, onde suas intervenções são freqüentes, já criticando, já defendendo verbas no Orçamento da União, pelo que conquistara no Exército grande número de amigos.

Curiosamente, foi, fora de dúvida, sua atuação na pasta do Exército, que fêz transcender de seu momento histórico o nome de Pandiá Calógeras: já por ter sido o primeiro titular civil nesse cargo, no período republicano; ${ }^{15}$ já, sobretudo, por sua obra, verdadeiramente extraordinária, ali realizada, com implicações indiscutíveis na História do Exército brasileiro.

12. Rodrigo Otávio e Raul Fernandes.

13. Eleito para um segundo período presidencial, a enfermidade impediu-o de comparecer ao ato de posse, no qual estêve representado pelo Vice-Presidente Delfim Moreira, que o substituiria, a menos de dois meses, em caráter transitório, face ao seu falecimento, antes, que pudesse ser empossado. $\mathrm{Na}$ imposslbilidade de efetivação do Vice, pelo curto período de Govêrno, fol promovida a eleição de nôvo Presidente, recaindo a escolha sôbre Epitácio Pessoa, empossado a 28-7-1919.

14. In ob. cit.

15. A nomeação de Alfredo Pinto Vieira de Melo, que Ihe guardou o lugar, foi feita em caráter interino (28-7 a 3-10-1919). 
O Presidente Epitácio Pessoa arcara com o ônus de sua atitude colocando civis nas pastas militares: Calógeras, no Exército, precedido, interinamente, por A. P. Vieira de Melo; e Raul Soares, na Marinha, sucedido por Veiga Miranda; mas, também êles, haveriam de contribuir com sua parcela de animosidade de certos setores militares, tendo de enfrentar as reservas de uns, a hostilidade de outros, e, até, a discreta obstrução de sua ação.

A atividade de Calógeras na direção do Ministério do Exército seria marcada, desde logo, pela substituição de tôda uma infra-estrutura obsoleta e insuficiente; provocando natural oposição, muda, mas forte, que êle procurou vencer, por meio de realizações, evidenciando a autenticidade de seus propósitos, na lhaneza de seu trato, na determinação construtiva, e na orientação patriótica. Em pouco tempo, havia substituído a própria mentalidade da corporação, do que resultou esta significativa apreciação do General Cândido Rondon: "O General Civil demonstrou que melhor amigo e mais carinhoso camarada não poderiam ter os oficiais do nosso glorioso Exército nacional. Calógeras conquistou a simpatia de seus adversários em dois tempos". 16

De um modo geral, promoveu "a reforma da instrução dos quadros e da tropa" - sintetizaram Theodorico Lopes e Gentil Torres. "Alteram-se a divisão territorial militar e a organização das divisões do Exército; reorganiza-se a artilharia de Costa; organiza-se a Diretoria-Geral de Intendência da Guerra e a Instrução Física Militar para tôdas as Armas; institui-se a Escola de Aperfeiçoamento de Oficiais. O trabalho de remodelação estende-se a todos os setores, traduzindo-se em regulamentação baixada para a Escola de Estado-Maior, para a Escola de Aviação, para a de Veterinária, para os Colégios Militares, para o Estado-Maior do Exército, para os grandes Comandos, Comandos de Brigadas, para a Imprensa Militar, para os Serviços de Campanha, de Transmissões, de Intendência, de Veterinária, de Material Bélico, de Saúde, de Administração de Corpos e Estabelecimentos Militares, Oficiais da Reserva e das Coudelarias.

"No que se refere ao material, fazem-se grandes aquisições para as diversas Armas e Serviços. Na Aviação já se podem organizar Esquadrilhas de Aviões de Caça e outros tipos. Incrementam-se indústrias militares, sobretudo as instalações

16. Apud E. M. de Castro e Silva, in Ả Margem do Ministério Calógeras (na Pasta de Guerra), 1961. 
de Piquête e Realengo. Cuidados muito especiais são pelo Ministro Calógeras dedicados ao problema do aquartelamento da tropa e das instalações de serviços. Com êsse objetivo cêrca de cem obras militares são atacadas e concluídas em diversos pontos do País". ${ }^{17}$

E da Instrução ministrada pela Missão Militar Francesa, chefiada pelo jovem general Gamelin - atualizado com a experiência da Guerra recente, com a cooperação do EstadoMaior, ressurge o Exército brasileiro, já então completado em seus quadros, reaparelhado, disciplinado na base de um Código de Organização Judiciária e um Código de Processo Militar, de iniciativa do Ministro Civil João Pandiá Calógeras.

Ao deixar a pasta a 15 de novembro de 1922, 18 havia, em três anos e quatro meses, transformado êsse Exército, consolidando-o, depois de se ter sobreposto às crises, de ter superado recalques e de vencer ressentimentos e desafeições; emergindo daquele instante de sua vida, engrandecido pela soma geral de suas realizações, pela inquestionável capacidade de liderança, que levara seu amigo Martin Francisco Ribeiro de Andrada a julgá-lo capaz de ser "Ministro para qualquer pasta, em qualquer país do mundo"; 19 sendo, sem dúvida, adequada, a qualificação de "General Civil" que Ihe deu Rondon, Calógeras se havia credenciado para a admiração do Futuro, que é bem nosso presente.

Encerrada a sua missão no Ministério do Exército, com o término do mandato do presidente Epitácio Pessoa, procurou afastar-se da vida pública e dedicar-se aos seus próprios interêsses, como industrial, sem cessar, entretanto, a atividade intelectual, colaborando para a imprensa, ou preparando novos livros, acrescentando à sua bibliografia científica e técnica trabalhos de grande significação histórica e literária, vazados num estilo sóbrio, erudito e comunicativo.

São dessa época (1926/1930), além de inumeráveis conferências, seus livros mais característicos, como Política Exterior do Império (3 vols.), Problemas de Govêrno, Formação Histórica do Brasil e Res Nostra - neste, aliás, onde reúne trabalhos diversos divulgados na imprensa, que revelam a cultura densa e

17. In Ministros da Guerra do Brasil (1808/1950), 4ạ edição, 1950.

18. Assumira o cargo de Ministro do Exército a 3-10-1919, ao regressar da Europa, das missões diplomáticas que Ihe foram confiadas. Desde sua posse, só se afastara eventualmente do cargo entre 22-3 e 15-4-1922, durante cuja ausência respondeu pela Pasta João Pedro Veiga Miranda titular da Pasta da Marinha, onde substituíra outro civil, Raul Soares.

19. Apud Antônio Gontijo de Carvalho, in ob. cit. 
vária; era o aproveitamento de sua energia mal contida, desde que se afastara da atividade político-administrativa, transformando-a em produção literária.

Em verdade, nem mesmo quando mais intensa foi sua ação como homem público, afastou-se do trabalho intelectual. A prova, no-la dá a Fundação "Pandiá Calógeras" - fundada, após sua morte, por iniciativa de seu amigo Roberto Simonsen que registrou 68 títulos de livros e monografias de sua autoria, ${ }^{20}$ entre os quais, além dos já citados, vale destacar, ainda, Os Jesuítas e o Ensino - no qual responsabiliza a Companhia de Jesus de deformar a instrução e estrangular quaisquer iniciativas do ensino leigo; que, no entanto, êle próprio contraditaria em seu último livro Ascensões d'Alma, de 1934, que assinala sua conversão ao catolicismo; e Relações Exteriores do Brasil, Rio Branco e a Política Exterior, Novos Rumos Econômicos, Problemas de Govêrno, Conceito Cristão do Trabalho, Problemas de Administração (Relatório confidencial ao Presidente Conselheiro Rodrigues Alves sôbre a situação Administrativa do Brasil, depois liberado) e seu estudo biográfico Marquês de Barbacena.

Estivera na Europa em princípios de 1923, em atendimento dos interêsses da indústria de artefatos de cobre, organizada por um grupo financeiro paulista, liderado por Roberto Simonsen, que the dera pequena participação, com a responsabilidade da direção. De volta, entre sua atividade industrial e a atenção aos problemas político-econômicos nacionais, completava seu tempo com colaboração regular para a imprensa, notadamente para o "O Jornal", no Rio de Janeiro - GB, de seu amigo Assis Chateaubriand. Não escondia a um e outro amigo mais íntimos, seu pesar pelo ostracismo político que Ihe haviam impôsto, conservando, porém, erguida a cabeça, sem condescender com a mediocridade, sem aviltar-se para obter posições no que só lucraria a Pátria, que nela teve um místico adorador.

$\mathrm{Na}$ retorta do Tempo, seus atos estratificados, e precipitados com a inteireza de seu caráter e a adequação de suas atitudes administrativas, produziriam, em essência, o reconhecimento da excepcionalidade de seu vulto, exigindo a reverência dos pósteros.

Vale registrar o fato de que passados 43 anos, desde que se afastou do Ministério do Exército - que o transformou, re-

20. In Calógeras na Opinião de seus Contemporâneos, Roberto Simonsen e outros, Fundação "Pandiá Calógeras", 1935. 
criando-o, nêle implantando os alicerces de sua eficiência e seu valor como instrumento da defesa nacional e das instituições democráticas brasileiras - jamais alguém procurou identificálo com a obra admirável que ali realizou; até que, em 1965, o presidente Marechal Humberto de Alencar Castelo Branco determinou que fôsse o seu nome dado ao Estabelecimento Central de Subsistência do Exército (Decreto n.? 56.593, de 21-7-65); e recentemente, o presidente General Emílio Garrastazu Médici promoveu a emissão de um sêlo comemorativo do centenário de seu nascimento.

Coerentemente, Calógeras se pusera ao lado do seu velho amigo Olegário Maciel, participando da Aliança Liberal. E com a vitória da Revolução de outubro de 1930 , foi convidado a integrar, como civil, em representação de Minas Gerais, a Junta Governativa, ${ }^{21}$ que substituiu o deposto presidente Washington Luís. Recusando a consideração, preferiu manter-se em atitude de expectação, que iria levá-lo, logo depois, à oposição frontal à Ditadura; e, inevitàvelmente, a apoiar São Paulo na Revolução Constitucionalista. Simbòlicamente, porém, de vez que suas condições físicas já não mais lhe permitiam uma participação pessoal e ativa.

Sua oposição a Getúlio Vargas, e a posição tomada em relação ao movimento paulista de 9 de julho de 1932, não o tornaram mal-querido do Ditador - que, a bem da verdade, se diga: não era homem para guardar rancores - que sem embargo da recusada ajuda eleitoral que the mandou oferecer, iria apoiar sua candidatura à Assembléia Constituinte, convocada em 1933, tendo Calógeras conseguido a maior votação já obtida, até então, por um candidato ao Congresso Nacional; participando, uma vez mais, da representação de Minas. Essa consagração eleitoral haveria de balsamizar-lhe o íntimo ferido pelo ostracismo em que foi mantido através de um decênio.

Assumira o mandato já bastante enfêrmo; por isso que era irregular em sua freqüencia ao plenário. As vêzes que ali comparecia, o fazia apoiado numa bengala ou no braço de um amigo, sensivel e progressivamente debilitado, vindo de Petrópolis - RJ - para onde se transferira com a espôsa, em busca de melhoria de condições físicas. Foi ali que o vi algumas vêzes, no exercício de minha função profissional de jornalista: e numa tarde, como o tivesse encontrado na Sala do Café, dêle aproximei-me fazendo questão de aperta sua mão. Tenho, hoje,

21. V. Pandiá Calógeras, de Luiz Pinto, DASP, 1955. 
a impressão de que foi a última vez que Calógeras estêve no Palácio Tiradentes, porque deixei de vê-lo, desde então.

Não teve Calógeras a oportunidade de apor sua assinatura, entre os demais, no texto da Constituição de 7 de julho de 1934, porque a morte interferira, levando-o para além da Vida, a 21 de abril de 1934. Na sessão consagrada à sua homenagem falaram vários oradores, mas nenhum deu as exatas dimensões de seu vulto, que ficou entre os maiores do Brasil. 